at $45^{\circ}$ and its rather rapid variation with energy. The calculated values are intermediate between White's and those of Tuve, Hafstad and Heydenburg ${ }^{3}$, and as a qualitative explanation this seems as successful as that already given by Present ${ }^{4}$ in terms of exchange forces. This is not strong evidence for Infeld's theory, since the main effect at these energies-up to $1,000 \mathrm{kv}$.-is due to the large repulsion at small distances near the critical radius $r_{0}\left(1.9 \times 10^{-13} \mathrm{~cm}.\right)$.

The interpretation of the scattering intensities by means of potential fields is not, moreover, incompatible with the existence of stable energy levels or of resonance levels which may be used in tentative models of compound nuclei, since the known binding energies and the phase-shifts of zero order can be reproduced with strong attractive forces at radii which need not exceed $2 \times 10^{-13} \mathrm{~cm}$. The binding energies are not greatly affected by introducing longrange forces as well.

Forms of potential field which will meet all of these requirements in detail must await further investigation.

C. B. O. MOHR.

G. E. Pringle.

Cavendish Laboratory,

Cambridge. May 5.

1 Phys. Rev., 49, 309 (1936).

2 Proc. Camb. Phil. Soc., 32, 127 (1936)

${ }^{3}$ Phys. Rev., 49, 402 (1936).

t ibid., 48, 919 (1935).

\section{Return of Radio Waves from the Middle Atmosphere}

WE are glad to be able to confirm and amplify the indications given by Prof. R. C. Colwell and A. W. Friend in the letter which appeared in NATURE of May 9. One of us, in his address, as chairman, to the Wireless Section of the Institution of Electrical Engineers ${ }^{1}$, has reported briefly on the initial stages of work for the Radio Research Board undertaken recently at Orfordness, a site the isolation of which permitted the use of substantial powers in shortduration pulses for the closer study of the lower regions of the ionosphere. In addition to the sporadic reflections from levels between $85 \mathrm{~km}$. and $100 \mathrm{~km}$. then reported, we have had under intermittent observation the very complex echo-systems which result from the return of radio waves from heights between $6 \mathrm{~km}$. and $60 \mathrm{~km}$.

We had, just before publication of the letter of Prof. Colwell and Mr. Friend, completed a preliminary communication on these studies, which we hope may be published at a very early date. Meanwhile we may say that we incline to recognise three distinct regions from which radio waves, up to very high frequencies, are returned within the range of height $6-60 \mathrm{~km}$. The echoes from the lowest heights appear to belong to a system of multiple reflections from sharply defined heights which usually lie above $6 \mathrm{~km}$., are not infrequently found at $10 \mathrm{~km}$., and on a single occasion have been found so high as $14 \mathrm{~km}$.

A second and apparently independent group of echoes returns from levels between $15 \mathrm{~km}$. and $50 \mathrm{~km}$., and we show in our forthcoming communica. tion that this region is almost certainly replenished by local thunderstorms. The thunderstorm mechanism is probably involved also in the replenishment of the lower region, but much further study is necessary before the evidence about these two regions is unravelled; this remark applies, with perhaps greater force, to a third region which we recognise at about $60 \mathrm{~km}$. This third region does not appear to be very closely related to either of the other two ; it cannot, for example, be dismissed as a misinterpretation of second-order echoes from the $30 \mathrm{~km}$. region.

Our work, which began in May 1935, and in which heights were first measured with some certainty on June 10, 1935, has been carried on to complete a year's observation, mainly in the frequency range 6-12 me./sec.; in some isolated trials on notably higher frequencies-including those proposed for television services-we have not yet attained a frequency so high that its return from the middle atmosphere can be regarded as unusual.

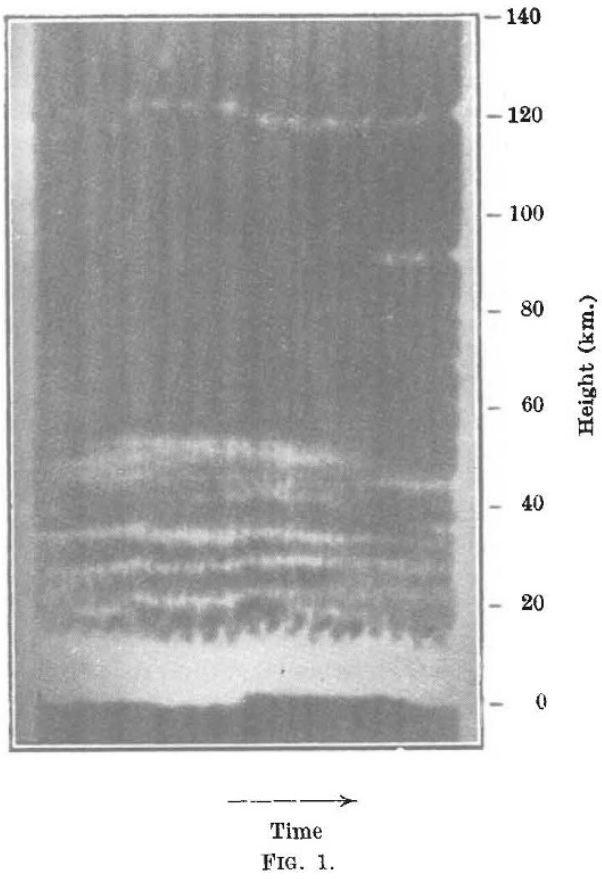

The accompanying illustration (Fig. 1) is a direct untouched reproduction from a continuous record of equivalent path against time $\left(P^{\prime} t\right)$; the portion reproduced covers two minutes in time near 0700 G.M.T. on July 5, 1935, and shows echoes, on a $6 \mathrm{mc} . / \mathrm{sec}$. frequency, which includes, in addition to the ground ray response and the known $E$-region echoes, a series of multiple reflections from the low heights now under discussion, together with echoes at intermediate heights which cannot, we suggest, be fitted into one or two simple series of multiple reflections.

This work has been undertaken as part of the programme of the Radio Research Board and this note is published by permission of the Department of Scientific and Industrial Research.

R. A. Watson Watt.

L. H. BAINBRIDGE-BeLl.

A. F. WrikINs.

E. G. Bowen.

National Physical Laboratory, Teddington, Middlesex.

$$
\text { May } 14 .
$$

${ }^{1}$ J. Inst. Elec. Eng., 78, 10 (1936). 